\title{
Methods and Methodologies for Improvised Speaking Skills
}

\author{
D. J. B. Esther \\ Department of English, Jerusalem College of Engineering, Chennai, Tamil Nadu, India.
}

\begin{abstract}
The importance of English cannot be neglected and denied as it the most common language spoken all over the world. Speaking skill plays a vital role in the career of a student. Many talented and deserving candidates miss their job opportunities because of their poor speaking skill. English is essential in each and every field and students should know to communicate English effectively. To speak English fluently, one should possess good practice. They should train themselves to speak English with a good accent. There are students who confine themselves within a circle and hesitate to speak English. The language learners feel embarrassed to speak though they possess good language.

A talented student who has good technical knowledge is unable present the same as he lacks in speaking skill. There are so many unanswered questions because of their fear for language. Students from rural areas have problems in learning and speaking English. They do not have enough exposure to spoken English and most of the students are least bothered about their speaking skill. Proficiency in language needs interest, self motivation and self confidence. Language learners who lack confidence should participate in discussions to come out of the shell. This paper discusses the barriers and the techniques to overcome the same and to acquire the speaking skill for their successful career.
\end{abstract}

Keywords: Career, communication, ELT, language, Speaking, vocabulary

\section{Introduction}

Speaking is the most important of all other communication skills. Transfer of knowledge, ideas and information occurs in the form of speech. Language is a tool for communication. There are so many languages spoken all over the world. English is an international language and business language which is used in technology and in working world. It is the official language in most of the countries and it is accepted worldwide. It has an international standard and it is indispensable to learn the language for survival and pride. Speaking English is extremely important to all, especially students. Students with good speaking skills are always appreciated and they express their ideas effectively. The sender can make the receiver understand exactly his ideas by effective communication. Students with good speaking skills are able to get their favorite job related to their field. The personality of a person is highlighted when he learns and speaks the language perfectly. If a person wants to shine in his field, it is mandatory that he should possess a good language which makes him confident to face the competition in job hunt. Proficiency in language provides a person the feel of confidence.

\section{Importance of speaking skills}

Nowadays, the importance language is known to everyone. In students' academic environment they face many situations which demand them to speak English. To converse with their professors, to give presentation, to answer viva-voce etc., they need to speak English. Similarly after completing their studies they must know to speak English to interact with all in their working environment. They must learn to speak English effectively. A person with better speaking skills will definitely have a greater chance. Employers always prefer the candidate who possesses excellent speaking skills. Technical knowledge of person will be of little use when he doesn't know to speak English. A person with good language will be considered and selected because he will be able to communicate properly with all and even with other country people. We have observed people with good language will be ahead in their profession. A person must possess speaking skills, whether he works in a business organization or in an educational institution or a student. In recruitment process, there are many steps involved to evaluate the ability of a candidate to speak English. In a person's career he encounters various situations which demand good speaking skills. The ability to make effective and impressive presentation is one of the most important qualities a person must develop for his successful career. Constant practice is important to acquire this skill. In a job interview the candidate must convince the employer that he suits the job than anybody else. Apart from technical knowledge and general knowledge, speaking skills is inevitable for both personal and organizational growth. The employer will evaluate how effectively the candidate presents his knowledge and ideas verbally. The candidate must possess good vocabulary and he must speak clearly in group discussion, which is another part of selection process. The candidate must know to use polite words and he should be 
assertive. The ideas should be expressed effectively. The language they possess should be accurate, simple and clear.

\section{Factors affecting speaking}

Though the importance of speaking English is known to everyone, most of the students do not take steps to improve their language. This is mainly because of lack of confidence. They hesitate to speak English as they do not have involvement and curiosity. They are reluctant to learn to speak English. Students do not have enough practice which is very important to speak a new language properly. Students studied in medium of regional languages assume that they can never develop fluency. Most of the students hesitate to speak English because they are not ready to accept publicly that they can't speak English as they relate it with personality and they feel their prestige will be offended. Students do not have self motivation. They realize the importance of English and they wish to speak English but they do not take steps to improve their language. Students from rural background learn English theoretically but they fail to use it practically. They are least exposed to English language. They learn English for examination purpose. Their aim is just to get through the paper. Students feel embarrassed when they commit mistake while speaking English, which is another important factor which prevents them to speak English. Mother tongue influence is another major problem. When students speak English they bring the sentence in their mind in mother tongue then they translate the same in English. As they are not so good at vocabulary, they miss the fluency and they struggle to use the exact words. It becomes difficult for them to speak what they think. Students have poor listening skills which is very important to speak. Students expect themselves to be very perfect. Also they become very conscious of using impressive words and they feel that they are not so sound with vocabulary. They start analysing their speech and they find fault in it. As they analyse their speech again and again, they get demotivated to speak English. Society around the students fail to support them to speak English. When they converse in English with their fellow mates they start to neglect them thinking that they are showing off. This makes the students lose their confidence to improve their language. As the students do not want them to be avoided by the people around and so they withhold the practice of speaking English.

\section{Steps to improve speaking skills}

To speak English fluently the language should be practiced regularly. Language should be introduced to the students from the beginning. Also the students from rural area must be encouraged to speak English. In such a way the system of education must be framed. The students can be asked to read stories. First they can start with small moral stories and then slowly they can read good fictions also. They will come across new words while reading books which certainly enrich their vocabulary and pave way to construct sentences using apt words. Student should not be taught to speak English based on grammatical rules. If they stick on to the rules of grammar, they normally confuse. Teachers' role is essential to make the students get involve to interact in English. Speaking activities can be given to the students. The activities must motivate the students to speak English and it should not be a boring session. It is the role of a teacher to convince the students that acquiring good language is not a hard nut to crack. Instead, it needs a little dedication and involvement. Students can be initiated to watch good English movies of their favorite stars which will definitely help them to speak English. They can also watch animation movies with sub titles which also aid them to improve their language. Students should read English newspaper daily. Dictionary should be referred regularly to learn and to know the meaning of new words.

\section{Conclusion}

To conclude students should realize the importance of English and they should acquire good speaking skills by following the steps in their daily life which are been discussed earlier. The duty of a teacher is to facilitate the language learning process of students. The curriculum should be framed in such a way that it should help the students to speak language with good accent. A person with good speaking skills undoubtedly can achieve a successful career.

\footnotetext{
References

[1]. Hetrakul, Kavin.1995.The Second Language.http://eserver.org/courses/spring/95/76-100g/kavinHetrakul.html (Accessed on October 28, 2005)

[2]. Kneen, J. (2011). Essential skills: Essential speaking and listening skills. New York, NY: Oxford University Press.
} 